\title{
A Long Term Effects of a New Onset Psychosis after DBS Treated with Quetiapine in a Patient with Parkinson's Disease
}

\author{
Sara Piccoli ${ }^{\circledR}$, Giulia Perini ${ }^{2,3}$, Silvia Pizzighello ${ }^{1}$, Alec Vestri', Giovanni Ferri², \\ Tommaso Toffanin ${ }^{2}$, Halima Follador ${ }^{2}$, and Andrea Martinuzzi ${ }^{1}$ \\ ${ }^{1}$ Rehabilitation Unit for the Acquired Neuropsychological Disorders, "E. Medea" Scientific Institute Conegliano-Pieve di Soligo Research Center, \\ Pieve di Soligo, Italy \\ ${ }^{2}$ Department of Mental Health ULSS 7, Pieve di Soligo, Italy \\ ${ }^{3}$ Department of Neuroscience, University of Padoua, Padoua, Italy
}

Deep Brain Stimulation represents a therapeutic option for PD patients. In this paper, we present and discuss a case of acute delirium and psychosis manifesting after DBS in a 58-years-old man affected by Parkinson's Disease. We highlight the importance of an exhaustive psychiatric evaluation in candidates for DBS and we underline the severity and non-reversibility of some adverse events associated with the implantation, suggesting the use of Quetiapine in the management of these effects. Acute psychosis may be listed as a potential severe adverse event associated with DBS, even in patients without a clear cut previous history of psychiatric disorders.

Psychiatry Investig 2015;12(1):146-149

Key Words Behavioural symptoms, Deep brain stimulation, Parkinson's disease, Neuropsychiatry, Neuropsychology, Psychopharmacology.

\section{INTRODUCTION}

Deep Brain Stimulation represents a therapeutic option for neurological and psychiatric diseases such as PD and Obsessive-Compulsive Disorder (OCD). ${ }^{1}$ Its effects on motor symptoms and quality of life of advanced PD are well established ${ }^{2}$ and, at least for young-onset patients, seems to last at 10 year follow-up. ${ }^{3}$ At the earlier stage of the disease, neurostimulation in combination with medical therapy improves motor symptoms better than medical therapy alone. ${ }^{4}$ Despite this, the effects of DBS on the cognitive and neuropsychiatric symptoms are controversial.

Neuropsychological complications may include deficits in focal attention, language, ${ }^{5}$ speed of mental processing, working memory, phonemic fluency, visuo-spatial ability and long

Received: October 9, 2013 Revised: December 27, 2013

Accepted: December 27, 2013 Available online: January 12, 2015

$\triangle$ Correspondence: Sara Piccoli, MD, PhD

Unit for the Rehabilitation of Neuropsychological Disorders "E. Medea" Scientific Institute Conegliano-Pieve di Soligo Research Center, Via Montegrappa, 96 31053-Pieve di Soligo (TV), Italy

Tel: +3904389062, Fax: +390438980444, E-mail: sara.piccoli@ps.lnf.it

(a) This is an Open Access article distributed under the terms of the Creative Commons Attribution Non-Commercial License (http://creativecommons.org/licenses/by$\mathrm{nc} / 3.0$ ) which permits unrestricted non-commercial use, distribution, and reproduction in any medium, provided the original work is properly cited. term consolidation of verbal material..$^{6-9}$

Psychiatric changes after DBS may include: mania, ${ }^{10}$ hypomania, ${ }^{11,12}$ depression, ${ }^{13-16}$ psychosis, ${ }^{17,18}$ and increased risk of suicide. $^{4,19,20}$

The frequency of these side-effects is not clearly established. It has been suggested that their occurrence is overestimated because of reporting bias. ${ }^{21,22}$

We here describe a peculiar case in which STN-DBS activation triggered acute delirium leading to long term neuropsychiatric impairment.

\section{CASE}

We describe a 58 years old man, affected by Parkinson's Disease (PD), who developed new-onset acute delirium and psychosis after Deep Brain Stimulation (DBS) implantation requiring hospitalization in the psychiatric inpatient unit of our Dept of Psychiatry. He was than transferred for treatment in our Unit of Neurorehabilitation three months after surgery.

He presented a 10 year history of PD requiring pharmacological treatment and a previous diagnosis of Lyme disease (with persistent anti Borrelia antibodies but no signs of active disease). Despite the symptoms of PD, he lived alone and was independent in Activity Daily Living (ADL); he had recently 
retired from work due to the incoming motor impairment (he was a general practitioner) but was socially very active. Neuropsychological assessment before implantation showed Mini Mental State Examination (MMSE) within normal range for age and education (24.2/30) even if, considering the high level of schooling, it was reasonable to attend a higher score. Indeed, the neuropsychologist observed considerable performance anxiety, hasty approach, impulsive behavior and, sometimes, confusion about the test.

In his pre-implantation history, the sister reported some signs which could have suggested an underlying bipolar disorder. As a child he was reported as hyperactive and accidentprone and in adulthood he was overtly hyperthymic, his sleepwake rhythm was altered, he self managed his pharmacological therapy without respecting indications and, from time to time, he suddenly interrupted his activity, disappearing for some days without warning anyone. Despite this, no contact with Psychiatric Services was reported. Patient's medication regimen included Levodopa/Carbidopa oral therapy for PD.

Due to the exclusion of overt psychiatric or cognitive impairments, DBS was evaluated as a useful therapeutic option for the patient and, few days after implantation bilaterally in the subthalamic nucleus (STN), it was switched on.

Within 48 hours the patient showed signs of new-onset psychosis: delusions, hallucinations, confusion and very aggressive behavior. Stimulation was immediately switched off, and treatment with Quetiapine had been started by the psychiatric consultant, with no response. Due to the persistence of the delirium, he was admitted to our Psychiatric Unit for a re-evaluation of the psychiatric diagnosis and treatment. At admission he was disoriented, with loosening of associations, delusions and hallucinations, severe mood instability, insomnia and his behavior was severely disturbed, with self injurious manifestations. He was treated with Clozapine (from 50 to $100 \mathrm{mg} /$ day) and Valproate (from $1000 \mathrm{mg} /$ day to 1500 $\mathrm{mg} /$ day). Levodopa/Carbidopa therapy remained unchanged. A CT scan was negative for lesions and confirmed the presence of bilateral electrodes in the subthalamic area caudally the mesencephalon. After two days, he presented an adverse reaction to Clozapine that required interruption of antipsychotic treatment. The assessment at admission included: scales for the cognitive level [MMSE, Level of Cognitive Functioning (LCF)], disability [Disability Rating Scale (DRS), Functional Independence Measure (FIM), Unified Parkinson Disease Rating Scale (UPDRS)] and behaviour [Agitated Behaviour Scale (ABS) and Delirium Rating Scale (DelRS)], see Table 1.

Given the previous reaction to Clozapine the patient was started on Quetiapine (from $25 \mathrm{mg}$ to $300 \mathrm{mg}$ in four weeks). The initial dose was $25 \mathrm{mg}$; the speed of titration was limited by previous hyper CK (642 U/L, normal range 49-397) and the maximum dose of $300 \mathrm{mg}$ was reached in four weeks. No adverse reaction (clinical or haematological) was observed. DBS was always in the off mode.

Cerebral spinal fluid exam was negative for CNS infection or inflammation. Due to the previous diagnosis of Lyme disease, even in absence of signs of active disease, an i.v. cycle of penicillin was then administered with no clinical change. EEG showed a generalised slowing without irritative abnormalities.

The patient started intensive neuropsychological, physical and occupational rehabilitation lasting for three months. Daily behaviour was monitored during hospitalization with ABS. The initial phase was dominated by many episodes of agitation and aggression, in particular verbal hetero-direct aggression, then the patient gradually adapted to different situations and his tolerance improved.

During treatment, his severe impairment of consciousness evolved to increasing signs of self-awareness. Brain imaging (CT) showed no focal densitometric modifications or accumulation of contrast agent in the area of electrodes implantation.

The patient gradually improved. Delusions were reduced and aggressive behavior almost disappeared: the ABS went from 25 at admission (weekly average score) to 17 (absence of agitation) at discharge.

Disability remained very severe (DRS 17/30); the LCF was 5/8 (confused-inappropriate improved from the initial 3/7-localized response); FIM was 51/126; UPDRS I-II was unchanged; UPDRS-III improved to 63. See Table 1.

At one year follow up after implantation, the DBS was always off and the behavioral disorder needed continuous and unchanged psychopharmacological treatment with Quetiap-

Table 1. Scores at admission and discharge

\begin{tabular}{lccc}
\hline \multicolumn{1}{c}{ Scale } & Admission & Discharge & Normal range \\
\hline MMSE & 7 & 11 & 24 \\
LCF & 3 & 5 & 8 \\
DRS & 18 & 17 & 0 \\
FIM & 29 & 51 & 126 \\
UPDRS I & 12 & 12 & 16 \\
UPDRS II & 22 & 22 & 52 \\
UPDRS III & 69 & 63 & 108 \\
ABS (one week) & 25 & 17 & 21 \\
DelRS & 34 & 23 & 11 \\
\hline
\end{tabular}

Scores at admission and discharge. CNC: Coma Near Coma Scale, MMSE: Mini Mental Scale Examination, LCF: Level of Cognitive Functioning, GOAT: Galveston Orientation Amnesia Test, DisRS: Disability Rating Scale, FIM: Functional Independence Measure, UPDRS: Unified Parkinson's disease rating scale, ABS: Agitated Behavior Scale, DelRS: Delirium Rating Scale 
ine at $300 \mathrm{mg} / \mathrm{die}$. The patient had not regained his previous level of functioning; his quality of life was extremely impaired needing help in most ADLs.

\section{DISCUSSION}

Most of the neuropsychiatric symptoms described in patient with PD treated by STN-DBS are transient and treatable, ${ }^{11}$ however, as in our patient, these manifestations may present acutely, be very severe, and result in long term irreversible disability. ${ }^{23}$

Risk factors may include male sex, early-onset $\mathrm{PD},{ }^{24}$ age, comorbidity with mood disorders, ${ }^{11}$ and psychological factors. $^{25,26}$

Complications after DBS may be multifactorial and may be linked to electrode position, neurotransmitter changes and primary psychiatric disorder progression. ${ }^{27}$

The STN is part of the cortico-subcortical network involved in the selection, stimulation, inhibition and regulation of movements, emotions, behavior and thoughts. Disorders are reported due to direct stimulation of these areas. ${ }^{28,29}$ More medial, ventral and anterior placement is associated to worsened neuropsychiatric outcomes ${ }^{10,30}$ and ventromedial electrode placement has been most consistently implicated in the induction of mania. Unipolar stimulation and higher voltage $(>3 \mathrm{~V})$ may also have a role. ${ }^{24}$ Involvement of the medial forebrain bundle is related to mania and depression, ${ }^{31}$ as well as left substantia nigra for depression; ${ }^{13}$ and the right frontal gyrus for apathy. ${ }^{32}$ Our case did not show special deviation from the typical trajectory and targeting usually applied for STN implantation.

Adverse effects can occur also with the DBS turned off, ${ }^{24}$ suggesting that surgical microlesions may be more relevant than stimulation. ${ }^{33}$ Small Intracerebral hemorrhage, as a possible adverse event, may accelerate the development of dementia and since age seems to be the major risk factor, it has been suggested to exclude PD patients above 70 years of age for DBS surgery. ${ }^{34}$

Alterations of neurotransmitters induced by STN DBS, as well as changes in post-surgery medication, have been considered in symptoms development. ${ }^{20,35}$ Finally, apparent side effects could instead result from progression of pre-existing cognitive or psychiatric problems, where DBS acts as worsening trigger or precipitating factor. ${ }^{36}$ It may be argued that lesioning of STN be a cause of delirium and may accelerate and magnify the negative cognitive evolution of a subthreshold bipolar disorder toward dementia syndrome. Indeed, it has been demonstrated that bipolar disorder, as well as depression, is linked with an higher risk of developing dementia. ${ }^{37}$

More controlled and prospective clinical observational studies, combined with accurate neuroimaging, are needed to identify clinical correlates and neurobiological mechanisms of STN DBS- induced confused mania. ${ }^{25}$

The possibility that the unusual manifestations were linked to co-morbidity (chronic Lyme disease) cannot be entirely excluded, but the absence of serology and CSF data indicative of active disease and the lack of response to antibiotic treatment argue against this hypothesis.

The case presented here suggests that more attention should be given to even soft signs of underlying mental conditions or mild cognitive impairment before surgery.

We treated our patient with Quetiapine, not only because he had an adverse reaction to Clozapine, but also because its use is well documented. It is a common first-line treatment for PD psychosis because of its tolerability, ease of use and demonstrated utility in open-label reports even if its efficacy has not been demonstrated in randomized controlled trials. ${ }^{38}$ Also for the treatment of delirium in general medicine and intensive care unit patients, Quetiapine appears to be an effective and safe agent. ${ }^{39}$ This case suggests that its use is adaptive also for PD patients with DBS.

Guidelines for DBS patient selection call for neuropsychological assessment, but are less prescriptive for psychiatric evaluation. ${ }^{40}$ In accord with Piasecki et al. ${ }^{27}$ who underlined the vital role of psychiatrists in the assessment and continuing care of DBS patients. We suggest that a comprehensive psychiatric pre-surgical evaluation and follow-up should always be included to carefully determinate mental conditions in any $\mathrm{PD}$ patient considered for DBS.

\section{REFERENCES}

1. Roh D, Chang WS, Chang JW, Kim CH. Long-term follow-up of deep brain stimulation for refractory obsessive-compulsive disorder. Psychiatry Res 2012;200:1067-1070.

2. Deuschl G, Schade-Brittinger C, Krack P, Volkmann J, Schäfer H, Bötzel K, et al. A randomized trial of deep- brain stimulation for Parkinson's disease. N Engl J Med 2006;355:896-908.

3. Castrioto A, Lozano AM, Poon YY, Lang AE, Fallis M, Moro E. Tenyear outcome of subthalamic stimulation in Parkinson disease: a blinded evaluation. Arch Neurol 2011;68:1550-1556.

4. Houeto JL, Damier P, Bejjani PB, Staedler C, Bonnet AM, Arnulf I, et al. Subthalamic stimulation in Parkinson disease: a multidisciplinary approach. Arch Neurol 2000;57:461-465.

5. Moretti R, Torre P, Antonello RM, Capus L, Gioulis M, Marsala SZ, et al. Cognitive changes following subthalamic nucleus stimulation in two patients with Parkinson disease. Percept Mot Skills 2002;95:477-486.

6. Saint-Cyr JA, Trépanier LL, Kumar R, Lozano AM, Lang AE. Neuropsychological consequences of chronic bilateral stimulation of the subthalamic nucleus in Parkinson's disease. Brain 2000;123:2091-2108.

7. Parsons TD, Rogers SA, Braaten AJ, Woods SP, Tröster AI. Cognitive sequelae of subthalamic nucleus deep brain stimulation in Parkinson's disease: a meta-analysis. Lancet Neurol 2006;5:578-588.

8. Alegret M, Junque C, Valldeoriola F, Vendrell P, Pilleri M, Tolosa E. Effects of bilateral subthalamic stimulation on cognitive function in Parkinson disease. Arch Neurol 2001;58:1223-1227. 
9. Trépanier LL, Kumar R, Lozano AM, Lang AE, Saint-Cyr JA. Neuropsychological outcome of GPi pallidotomy and GPi or STN deep brain stimulation in Parkinson's disease. Brain Cogn 2000;42:324-347.

10. Kulisevsky J, Berthier ML, Gironell A, Pascual-Sedano B, Molet J, Parés P. Mania following deep brain stimulation for Parkinson's disease. Neurology 2002;59:1421-1424.

11. Voon V, Kubu C, Krack P, Houeto JL, Tröster AI. Deep brain stimulation: neuropsychological and neuropsychiatric issues. Mov Disord 2006;21(Suppl 14):S305-S327.

12. Mandat TS, Hurwitz T, Honey CR. Hypomania as an adverse effect of subthalamic nucleus stimulation: report of two cases. Acta Neurochir (Wien) 2006;148:895-898.

13. Bejjani BP, Damier P, Arnulf I, Thivard L, Bonnet AM, Dormont D, et al. Transient acute depression induced by high-frequency deep-brain stimulation. N Engl J Med 1999;340:1476-1480.

14. Krack P, Batir A, Van Blercom N, Chabardes S, Fraix V, Ardouin C, et al. Five-year follow-up of bilateral stimulation of the subthalamic nucleus in advanced Parkinson's disease. N Engl J Med 2003;349:1925-1934.

15. Houeto JL, Mesnage V, Mallet L, Pillon B, Gargiulo M, du Moncel ST, et al. Behavioural disorders, Parkinson's disease and subthalamic stimulation. J Neurol Neurosururg Psychiatry 2002;72:701-707.

16. Volkmann J, Allert N, Voges J, Weiss PH, Freund HJ, Sturm V. Safety and efficacy of pallidal or subthalamic nucleus stimulation in advanced PD. Neurology 2001;56:548-551.

17. Doshi P, Bhargava P. Hypersexuality following subthalamic nucleus stimulation for Parkinson's disease. Neurol India 2008;56:474-476.

18. Herzog J, Reiff J, Krack P, Witt K, Schrader B, Müller D, et al. Manic episode with psychotic symptoms induced by subthalamic nucleus stimulation in a patient with Parkinson's disease. Mov Disord 2003;18:13821384.

19. Doshi PK, Chhaya N, Bhatt MH. Depression leading to attempted suicide following bilateral subthalamic nucleus stimulation for Parkinson's disease. Mov Disord 2002;17:1084-1085.

20. Schuepbach WM, Rau J, Knudsen K, Volkmann J, Krack P, Timmermann L, et al. Neurostimulation for Parkinson's disease with early motor complications. N Engl J Med 2013; 368:610-622.

21. Funkiewiez A, Ardouin C, Caputo E, Krack P, Fraix V, Klinger H, et al. Long term effects of bilateral subthalamic nucleus stimulation on cognitive function, mood, and behaviour in Parkinson's disease. J Neurol Neurosur Psychiatry 2004;75:834-839.

22. Funkiewiez A, Ardouin C, Krack P, Fraix V, Van Blercom N, Xie J, et al. Acute psychotropic effects of bilateral subthalamic nucleus stimulation and levodopa in Parkinson's disease. Mov Disord 2003;18:524-530.

23. Zonana J, Zimmerman M, McCarty SS, Ferrando S. A case of abruptonset apathy, psychosis, and depression following deep brain stimulation in a patient with Parkinson's disease. Psychosomatics 2011;52:463467.

24. Chopra A, Tye SJ, Lee KH, Sampson S, Matsumoto J, Adams A, et al. Underlying neurobiology and clinical correlates of mania status after subthalamic nucleus deep brain stimulation in Parkinson's disease: a review of the literature. J Neuropsychiatry Clin Neurosci 2012;24:102110.

25. Soulas T, Sultan S, Gurruchaga JM, Palfi S, Fénelon G. Depression and coping as predictors of change after deep brain stimulation in Parkinson's disease. World Neurosurg 2011;75:525-532.

26. Soulas T, Gurruchaga JM, Palfi S, Cesaro P, Nguyen JP, Fenelon G. Attempted and completed suicides after subthalamic nucleus stimulation for Parkinson disease. J Neurol Neurosurg Psychiatry 2008;79:952-954.

27. Piasecki SD, Jefferson JW. Psychiatric complications of deep brain stimulation for Parkinson's disease. J Clin Psychiatry 2004;65:845-849.

28. Maes H, Vingerhoets F, Berney A. Prevalence of mood disorders in Parkinson's disease patients treated with subthalamic nucleus deep brain stimulation. Rev Med Suisse 2011;7:385-388.

29. Volkmann J, Daniels C, Witt K. Neuropsychiatric effects of subthalamic neurostimulation in Parkinson disease. Nat Rev Neurol 2012;6:487498.

30. Tsai ST, Lin SH, Lin SZ, Chen JY, Lee CW, Chen SY. Neuropsychological effects after chronic subthalamic stimulation and the topography of the nucleus in Parkinson's disease. Neurosurgery 2007;61:1024-1029.

31. Coenen VA, Honey CR, Hurwitz T, Rahman AA, McMaster J, Bürgel U, et al. Medial forebrain bundle stimulation as a pathophysiological mechanism for hypomania in subthalamic nucleus deep brain stimulation for Parkinson's disease. Neurosurgery 2009;64:1106-1114.

32. Le Jeune F, Drapier D, Bourguignon A, Péron J, Mesbah H, Drapier S, et al. Subthalamic nucleus stimulation in Parkinson disease induces apathy: a PET study. Neurology 2009;73:1746-1751.

33. Okun MS, Fernandez HH, Wu SS, Kirsch-Darrow L, Bowers D, Bova F, et al. Cognition and mood in Parkinsons's disease in subthalamic nucleus versus globus pallidus interna deep brain stimulation: the COMPARE trial. Ann Neurol 2009;65:586-595.

34. Rektorova I, Hummelova Z, Balaz M. Dementia after DBS surgery: a case report and literature review. Parkinsons Dis 2011;2011:679283.

35. Alberts JL, Voelcker-Rehage C, Hallahan K, Vitek M, Bamzai R, Vitek JL. Bilateral subthalamic stimulation impairs cognitive-motor performance in Parkinson's disease patients. Brain 2008;131:3348-3360.

36. Eskandar EN, Cosgrove GR, Shinobu LA. Surgical treatment of Parkinson disease. JAMA 2001;286:3056-3059.

37. da Silva J, Gonçalves-Pereira M, Xavier M, Mukaetova-Ladinska EB. Affective disorders and risk of developing dementia: systematic review. Br J Psychiatry 2013;202:177-186.

38. Zahodne LB, Fernandez HH. Pathophysiology and treatment of psychosis in Parkinson's disease: a review. Drugs Aging 2008;25:665-682.

39. Hawkins SB, Bucklin M, Muzyk AJ. Quetiapine for the treatment of delirium. J Hosp Med 2013;8:215-220.

40. Defer GL, Widner H, Marié RM. Core assessment program for surgical interventional therapies in Parkinson's disease (CAPSIT-PD). Mov Disord 1999;14:572-584. 